\title{
Capsule Commentary on Woodfine et. al., Criteria for Hyponatremic Overcorrection: Systematic Review and Cohort Study of Emergently III Patients
}

\author{
Eilidh McAlister ${ }^{7}$ and Finlay A. McAlister, MD MSC ${ }^{2}$ \\ 'University of Toronto, Toronto, Canada; ${ }^{2}$ Division of General Internal Medicine, University of Alberta, Edmonton, Canada.
}

J Gen Intern Med 35(1):405

DOI: $10.1007 / \mathrm{s} 11606-019-05385-w$

(c) Society of General Internal Medicine 2019

\begin{abstract}
A lthough hyponatremia is common in hospitalized patients and is associated with prolonged lengths of stay and increased morbidity and mortality, ${ }^{1}$ it is potentially reversible. Indeed, hospital physicians devote a great deal of their time to calculating sodium deficits and choosing intravenous infusion rates. Until reading this interesting study by Woodfine and van Walraven, we did not realize the degree of potential variation in making these decisions: 9 different formulae for calculating sodium correction rates have been published, with surprisingly low correlations between each (as described in Woodfine's Tables 4 and 6), and there are 14 different definitions for "overly fast correction" in the literature, most based on studies of less than 75 patients. When these 14 definitions were retrospectively applied to a cohort of 624 patients treated for serum sodium less than $116 \mathrm{mmol} / \mathrm{L}$, Woodfine and van Walraven found that there was an elevenfold difference in the frequency of "overcorrection" (from 8.5 to $89.9 \%$ )! As the authors point out, this has implications both medico-legally and for quality of care. ${ }^{2}$

Although the authors were unable to examine which sodium correction equation is best to follow (that would require a substantially larger study to compare the frequency of osmotic demyelination syndrome with different sodium correction rates), this study represents an important first step in establishing the need for comparative effectiveness research in this field. Given this degree of heterogeneity in the published
\end{abstract}

Published online October 21, 2019 literature, it is highly likely that clinical practice varies even more. In an era focused on appropriateness of healthcare interventions, the paucity of outcomes research for something so common as the management of hyponatremia is surprising. Evidence-based medicine is not only relevant to the evaluation of drugs or devices, ${ }^{3}$ but should also be applied to the management of electrolyte disturbances and other such evidence grey zones ${ }^{4}$ that we encounter in everyday clinical practice. The management of hyponatremia brings to mind the words of William Osler: "If it were not for the great variability among individuals, medicine might as well be a science, not an art".

Corresponding Author: Finlay A. McAlister, MD MSC; Division of General Internal Medicine University of Alberta, Edmonton, Canada (e-mail: Finlay.McAlister@ualberta.ca).

\section{Compliance with Ethical Standards:}

Conflict of Interest: The authors declare that they do not have a conflict of interest.

\section{REFERENCES}

1. Wald R, Jaber BL, Price LL, Upadhyay A, Madias NE. Impact of hospitalassociated hyponatremia on selected outcomes. Arch Intern Med 2010; 170:294-302.

2. Woodfine JD, Walraven CV. Criteria for Hyponatremic Overcorrection: Systematic Review and Cohort Study of Emergently Ill Patients J Gen Intern Med 2019. https://doi.org/10.1007/s11606-019-05286-y

3. Straus SE, McAlister FA. Evidence-based medicine: a commentary on common criticisms. CMAJ. 2000;163:837-841.

4. Naylor CD. Grey zones of clinical practice: some limits to evidence-based medicine. Lancet. 1995;345:840-2.

Publisher's Note Springer Nature remains neutral with regard to jurisdictional claims in published maps and institutional affiliations. 